\title{
PROCESSING OF HIGH-RESOLUTION, SHALLOW SEISMIC PROFILES, GUANABARA BAY - RIO DE JANEIRO STATE, BRAZIL
}

\author{
Igor Kestemberg Marino ${ }^{1}$, Marco Antonio Cetale Santos ${ }^{2}$ and Cleverson Guizan Silva ${ }^{2}$
}

\begin{abstract}
This paper presents a proposal for implementing a processing flowchart for high-resolution single-channel seismic data acquired in Guanabara Bay, followed by its interpretation. Geologically, it consists of mapping the Guanabara Bay Quaternary deposits relative to the drowning of a fluvial paleochannel that resulted from recent sea level changes. So far, high-resolution seismic data have been interpreted without any signal improvement, while the development of a processing flowchart for this is hardly addressed in the literature. The parameters were selected based on the processing applied to conventional seismic prospecting for oil and gas in order to compose a less extensive and more applicable flowchart. The results confirmed the efficacy of the processing applied to shallow seismic data, with noise and multiples attenuation and better lateral continuity of reflectors in subsurface, thus increasing the quality of the final seismic record.
\end{abstract}

Keywords: Processing, shallow seismic, Guanabara Bay, high-resolution seismic.

RESUMO. 0 presente trabalho apresenta uma proposta de aplicação de um fluxo de processamento para dados de sísmica monocanal de alta resolução adquiridos na Baía de Guanabara e, posteriormente, sua interpretação. 0 objetivo geológico consiste no mapeamento dos depósitos Quaternários da Baía de Guanabara relativos ao afogamento de um paleocanal fluvial como consequência das variações recentes do nível do mar. Até o momento os dados de sísmica de alta resolução vêm sendo interpretados sem a aplicação de nenhuma melhoria e a elaboração de um fluxo de processamento para tal é raramente abordada na literatura. Os parâmetros foram selecionados para a elaboração do fluxo com base no processamento aplicado à sísmica convencional na prospecção de hidrocarbonetos de forma a compor um fluxo mais sucinto e aplicável. Os resultados obtidos nos perfis analisados comprovaram a eficácia do processamento de dados de sísmica rasa, com a atenuação de ruídos, das múltiplas de fundo e maior continuidade lateral dos refletores em subsuperfície, aumentando assim a qualidade do registro sísmico.

Palavras-chave: Processamento, sísmica rasa, baía da Guanabara, alta resolução sísmica.

\footnotetext{
1PGS - Rio Office, Rua São João, 25 Apto 712 - Centro, Niterói, RJ, Brazil. Phone: +55(21) 3628-0580 / +55(21) 99232-9889 - E-mail: igor.marino@gmail.com 2 Departamento de Geologia e Geofísica, Instituto de Geociências, UFF - Av Gen. Milton Tavares de Souza, s/n, Boa Viagem, 24210-346 Niterói, RJ, Brazil. Phone: 2629-5922 / 2629-5927 - E-mail: marcocetale@id.uff.br; cguizan@id.uff.br
} 


\section{INTRODUCTION}

In geophysics, the seismic reflection method is widely used in exploratory surveys to detect and map subsurface structures and interfaces. It consists basically in characterizing the depth of the reflecting surfaces and their influence on the wave speed on subsurface layers (Lowrie, 2006). A seismic source induces a signal at a certain known location, and its reflections on the interfaces between physically different layers are recorded for further analysis.

High-resolution seismic has very limited applicability at shallower depths (ten to hundred meters, in the case of lagoon, estuary and river surveys) and has better resolution than the conventional seismic, since it is able to image structures of centimeters (Brunetta, 2005). Methods and concepts from solid Earth geophysics are used in high-resolution seismic and its objective is generally addressing economic, technological and environmental issues. From the 70s and 80s, applied geophysics has also been used in engineering, hydrogeology and the environment, in order to investigate shallow targets. Usually, the noise content in highresolution data makes very difficult to interpret the seismic profile and justifies the application of processing techniques to treat the acquired data.

Until now, high-resolution, single-channel seismic data are being interpreted without any previous treatment, while studies and references in the area are quite rare, very recent or poorly addressed in the pertinent literature (e.g. Brunetta, 2005; Gomes et al., 2010). Based on these facts, this study presents a proposal for processing high-resolution seismic data that differs in several aspects from the conventional seismic processing flow. Based on certain parameters, such as the behavior of high frequency wave, acoustic impedance, applicability of filters to suppress typical background noise and gain recovery, it is possible to obtain a much higher quality seismic profile compared to the original data.

\section{STUDY AREA}

Guanabara Bay is located in Rio de Janeiro State, Brazil, between $22^{\circ} 40^{\prime}$ and $23^{\circ} 00^{\prime} S$ latitude and $43^{\circ} 00^{\prime}$ and $43^{\circ} 20^{\prime} \mathrm{W}$ longitude (Fig. 1). The total perimeter of $131 \mathrm{~km}$ extends up to $30 \mathrm{~km}$ from North to South and about $28 \mathrm{~km}$ from East to West (Kjerfveet et al., 1997), a narrowing of 1.6-km width can be observed between the São João Fort and Santa Cruz Fortress (Quaresma, 1997). It has an approximate area of $381 \mathrm{~km}^{2}$, up to its entry in the alignment between Santa Cruz and São João tips, with average water volume of $1,87 \times 109 \mathrm{~m}^{3}$. The bay presents a very complex bathymetry with a central channel that extends approximately $400 \mathrm{~m}$, with average maximum depth of $60 \mathrm{~m}$ nearby the inlet and a minimum of $5 \mathrm{~m}$ in the inner portion. The original shape of the study area is a consequence of the sea invasion and marine accumulation, initially identified by Ruellan (1944). From the twenty seismic profiles acquired in the study area, profiles 5 and 9 were selected because they include different portions of the study area with well-known sedimentary characteristics. Profile 9 consists of a Iongitudinal section with approximate $\mathrm{N}-\mathrm{S}$ orientation that extends from the entrance to the middle portion of the bay, while Profile 5 features a cross section of the Guanabara Bay extension, a central canal in the inner portion with preferential E-W orientation (Fig. 1).

Figure 2a shows key events and sedimentary deposits associated with the geological context of the study area during the Quaternary. The seismic profiles presented in this study provide evidence that covers from the end of a drainage paleosystem to the actual deposition system. During the last glacial period, about 20,000 - 18,000 A.P., Guanabara Bay underwent significant changes in its paleoenvironment. The fluvial deposits of the Caceribu Formation indicate that sea level was below the actual position up to $100 \mathrm{~m}$, dry climate, and a drainage system interlaced with shallow and wide channels. The coastline at this time would stand tens of kilometers toward the ocean (Fig. 2-b). The continental shelf was exposed to subaerial conditions where features typical of coastal areas developed. The current islands consisted of higher fragments of massif coastal ranges (Amador, 1997). About 16,000 B.P., the drowning process of the Pleistocene Basin started, thus marking the beginning of the Lower Holocene. This transgressive phase is called Guanabarina Transgression (Amador, 1980). At the peak of this transgression, between 5000 and 6000 A.P. (Bigarella, 1970, In: Amador, 1980), the bay had an area of $800 \mathrm{~km}^{2}$, relative sea level varied between 3 and $4 \mathrm{~m}$ above the current (Fig. 2-c).

According to Amador (1997), between 3800 and 3000 B.P., a new transgressive phase would have raised the sea level by about $1.5 \mathrm{~m}$ above its current level, being responsible for forming fossil beaches. At the rear of the shoreline, the bay primitive segments, truncated by the latest sedimentation, turned into lagoons. Furthermore, the tidal influence stretched over many kilometers into the bay allowing the development of extensive mangroves. However, more recent studies (Dias \& Kjerfve, 2008) show a nearly linear drop of the relative sea level during the last 5000 years.

Several authors infer that facies distribution affects significantly the seismic record, and it is possible to observe changes in the reflected signal characteristics and amount of energy depend- 


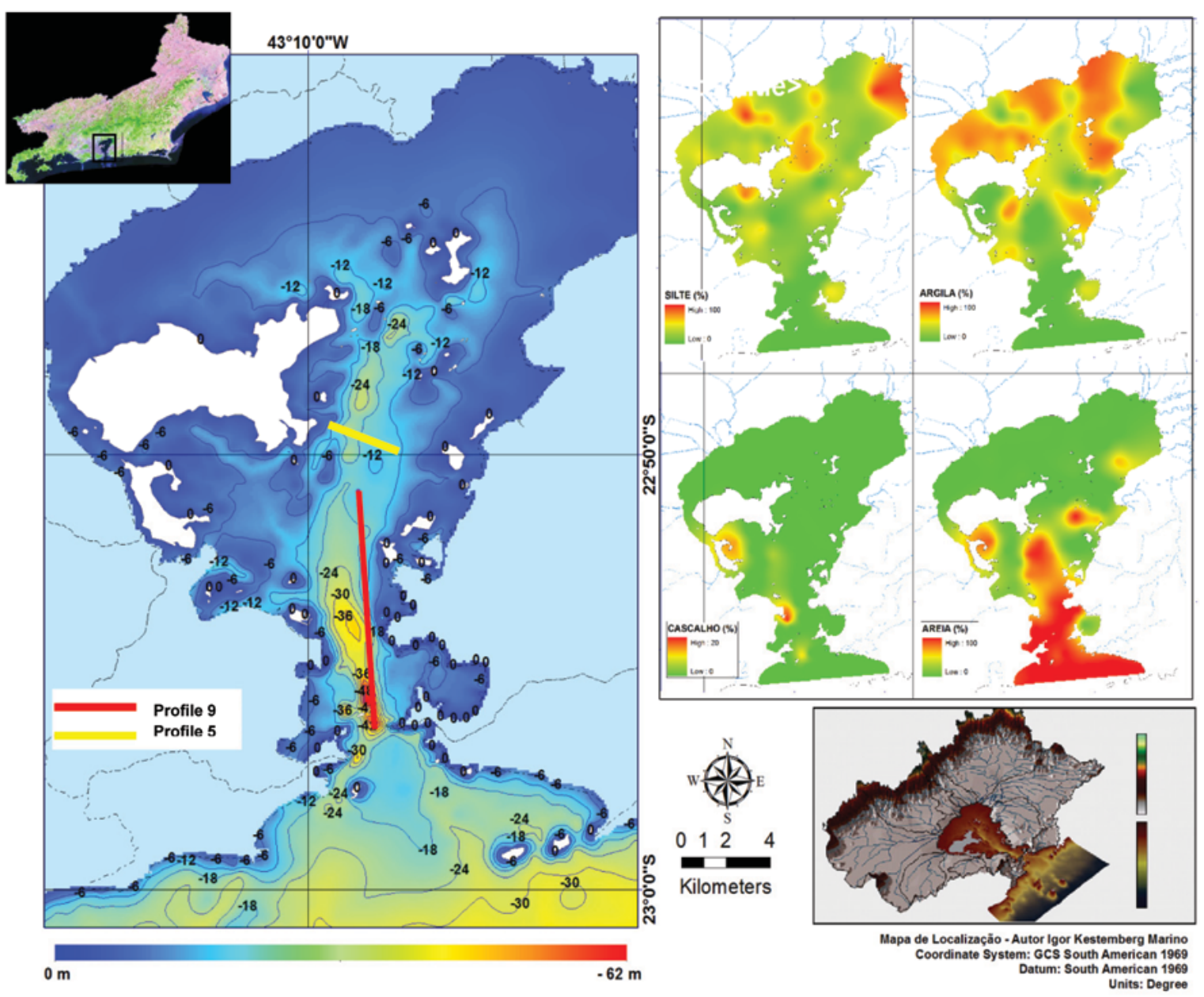

Figure 1 - Study site showing the isobathymetric line sand distribution of bottom sediments. Localization of profiles 5 (yellow) and 9 (red) selected to undergo data treatment through the steps of the processing flowchart.

ing on the type of bottom sediment and depositional acting processes (Baptista Neto et al., 1996; Quaresma et al., 2000; Catanzaro et al., 2004).

Coarse to medium lithoclast sand can be observed in a small strip that extends from the entrance of Guanabara Bay to the more central regions, also in isolated portions near to the llha do Governador and about $5 \mathrm{~km}$ from llha de Paquetá. Such distribution would result from the narrowing caused by morphology and increasing speed of tidal currents in the region (Amador, 1992; Quaresma, 1997). These sediments, located between the bay entrance and Rio - Niterói bridge, are related to the Pleistocene sands of the river system drowned by the last major transgression and reworked by the current hydrodynamic conditions. From the entrance of the bay to the outer portions, a large sandy bank with minimum $11 \mathrm{~m}$ isobaths can be observed.

Fine to very fine lithoclast sand is found along the entrance of the Jurujuba cove in Botafogo Bay and in the transition zone between the medium sand and terrigenous muds to the south of Rio - Niterói bridge. The presence of finer sands is justified by the lower velocities of tidal currents, due to the enlargement of the bay toward its inner portion (Quaresma, 1997).

Terrigenous muds, silts and clays are observed from the central portions, in the nearby areas of Rio - Niterói bridge to the bottom of the bay, and are related mainly to the speed of tidal currents, which are much lower in this region.

\section{METHODOLOGY}

The seismic data processed in this study were acquired using an EdgeTech CHIRP compartment-type profiler, with modulated frequency $(2-17 \mathrm{kHz})$. The equipment consists of a rigid aluminum plate attached to a coil spring specific for this type of survey. The device is attached to a maritime vehicle, which is towed and connected by cables to a computer / processor / ampli- 


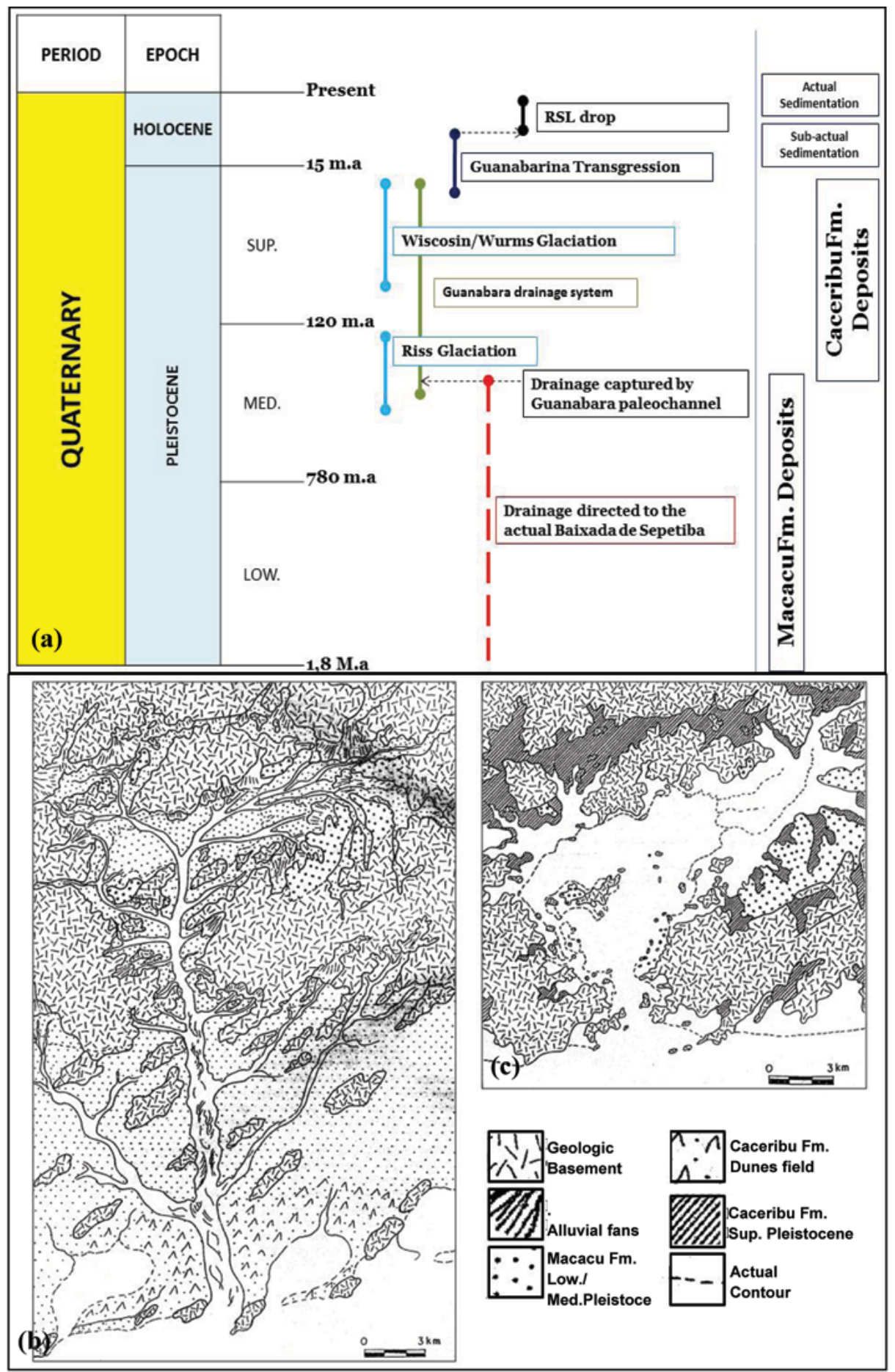

Figure 2 - Geochronology of Guanabara Bay during the Quaternary, associated deposits (Amador, 1980; Angulo \& Lessa, 1997) and respective Paleocene: (a) Last glacial period -20.000-18.000 A.P; (b) Maximum of the transgression-6.000-5.000 A.P. (modified from Amador, 1997).

fier integrated platform. The raw seismic section can be viewed at the time of acquisition in order to maintain survey quality control.

The Seismic Processing Workshop (Parallel Geosciences) software was used for the practical application of seismic data processing sequence. This software consists of a few basic steps to prepare a general flowchart and to optimize machine time. The Workflow and Seisview modules were used to elaborate the flowchart, visualize and interpret the post-processing seismic 
section and for quality control as well. The Vector Calculator module was used for plotting the data, analyzing the contents of signal amplitude frequency and spectrum.

The flowchart seen in Figure 3 was based on the processing applied to the conventional hydrocarbon seismic exploration, which is better adapted to the frequency content of shallow records and favored imaging of subsurface geological structures.

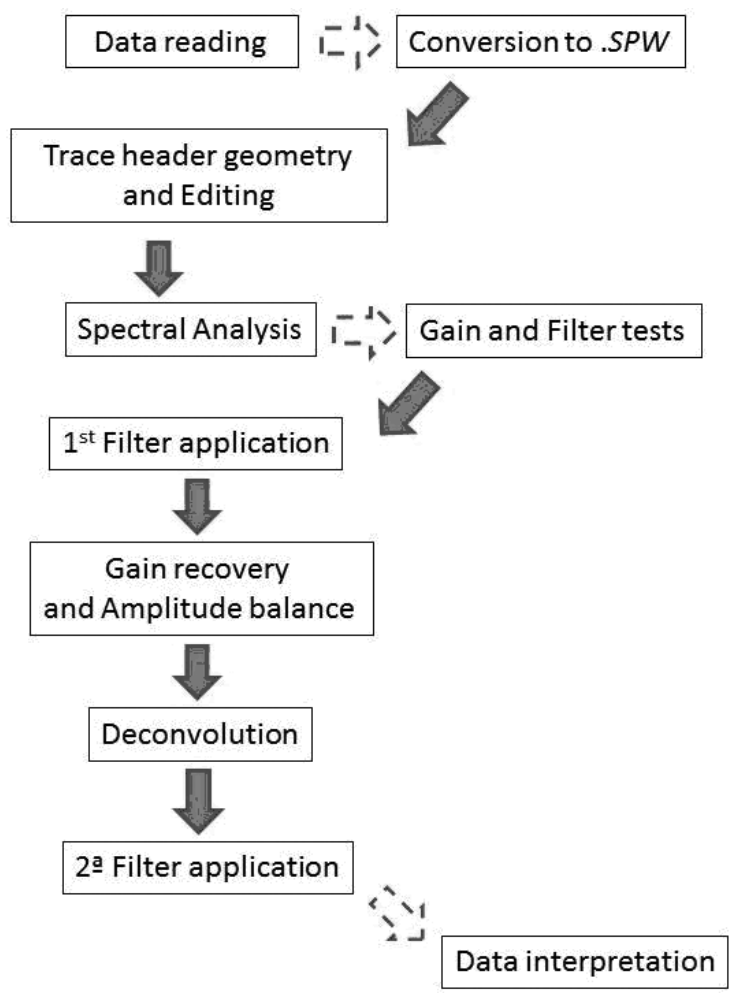

Figure 3 - Flowchart proposed for the processing steps taken to treat the seismic data.

In order to optimize the tests, fragments of the survey center line was used for test configuration and to determine the coefficients to be inserted, since no significant variations occur in the subsurface characteristics that can interfere with the adopted variables and parameters in the study area. The tests and comparisons made in both selected profiles show the best parameter configuration to apply the steps of filtering and recovering of energy decay over propagation time, which are better described further in this article.

The maps of textural characterization and distribution of bottom sediments were developed based on information from 92 bottom samples and 16 cores collected by Baptista Neto et al. (2006). For the data plotting step, a geographic information system (ARCGIS) was used, where the compiled data were inserted to generate grid maps of sedimentological parameters, bathymetric maps and coordinate system conversion.

\section{Data reading}

The data acquired with the Boomer equipment were initially recorded on the SEG-Y format according to predetermined equipment configuration, the seismic trace header contained only the information relative to the positioning of the source/receiver and gain adjustments.

In the initial stages, the selected seismic records were converted from the standard SEG-Y format to the internal format (.spw) file extension, and loaded using the $\mathrm{I} / 0$ Data Management module. The first viewing of the raw data is performed in Seisview module to define the scale patterns as shown in Figure 4. Profile 5 (Fig. 4-a) consists of 7445 traces, with sampling interval of 3.10-2ms and maximum recording time of $100 \mathrm{~ms}$, while profile 9 (Fig. 4-b) has 22180 traces, also sampled at intervals of 3.10-2ms and record up to $100 \mathrm{~ms}$. Adopting a constant value of $1500 \mathrm{~m} / \mathrm{s}$ for the propagation speed of the seismic pulse in shallow surveys (Barros, 2006), it may be inferred an acquisition maximum depth of about $75 \mathrm{~m}$ for both profiles.

The viewing patterns defined in this processing step do not change the final result, since no other type of output or processed data is generated. Once the initial stage is validated, the program updates the database and feeds the tables related to shots, receivers and seismic traces. In a second step, the input seismic file headers are updated from the information in the database, initiating the step for inserting the acquisition geometry and quality control.

\section{RESULTS AND DISCUSSIONS}

The main conventional processing steps were centralized and adapted to the high-resolution data, resulting in the following proposed flowchart: editing the SEG-Y record trace header, definition and quality control of acquisition geometry, data frequency spectrum analysis, testing filtering parameters, data cleaning and incoherent noise attenuation, amplitude normalization and gain recovery, attenuation of multiples, deconvolution, postdeconvolution filtering and as end product, the interpretation of seismic records.

\section{Trace header geometry and editing}

At this early processing step, the data regarding acquisition parameters such as shot coordinates and seismic signal receivers are inserted in the seismic trace header. Geometry insertion must precede any offset depending step and its definition avoids losses in the final product (Yilmaz, 1987).

The first correction of the geometry step consisted of transforming the coordinate system, from the original arc sec to 


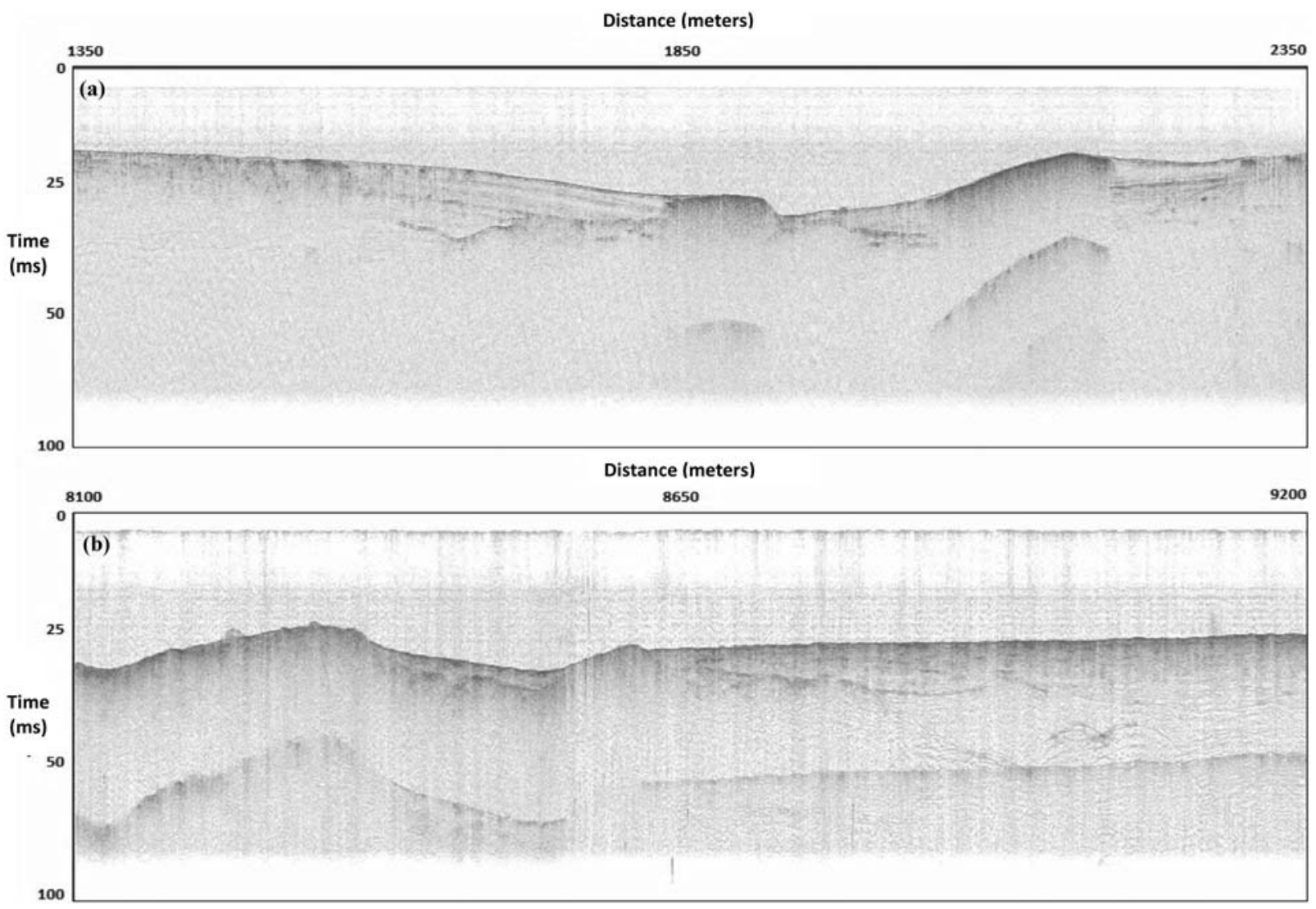

Figure 4 - Raw seismic profiles. Profile 5: offsets 1350-2350 (a), and profile 9: offsets 8100-9200 (b).

UTM coordinates and updating the new values into the headers of the stored traces in the program database. The values inserted in this step were: Survey ID, Trace Index and Field File, Source/Receiver Line, Source/Receiver Location, Trace Increment and Source/Receiver Elevation. The filling of these headers are very important since the different algorithms applied in the later steps use this data to move the windows of seismic trace analysis. Trace incremental distance was calculated using the average speed of the vessel (approximately $8 \mathrm{~km} / \mathrm{h}$ ) and shot rate $(6 / \mathrm{sec}-$ ond), being estimated at about $0.35 \mathrm{~m}$.

Immediately after inserting the geometry parameters, the water column was removed from the seismic record using the early muting tool, as seen in Figure 5. This removal can be very effective to optimize processing time and to minimize profile visual saturation since it removes the influence of fish schools, suspended sediment and debris, except in regions where certain phenomena in the water column should be identified, such as shallow gas seeps, commonly found in the study area (Fig. 6).

When the seismic profiler uses floats (and swell compensator) while being towed, topography can be corrected using the depth difference between the sensor and the air/water interface, with wave compensation and tidal variation. When floats are not used, as in the present work, topography can be corrected using bathymetric data and tidal tables, which were correlated to the trace signals in the reflector of the water/seafloor interface.

\section{Spectral analysis and amplitude balance}

The signal captured during seismic acquisition presents incoherent noises arising from environmental, instrumental or even anthropogenic interferences (Robinson \& Treitel, 1980). These noises impair the identification of subsurface structures degrading the quality of the final section and greatly reducing the signal/noise ratio. According to Houlding (1994), in high-resolution seismic profiling most of the noise present in the signal has amplitude values very close to the natural amplitudes, therefore, making it difficult to detect and remove the noise during data treatment.

The discrete Fourier transform enables the conversion of a seismic signal into a complex function containing information 


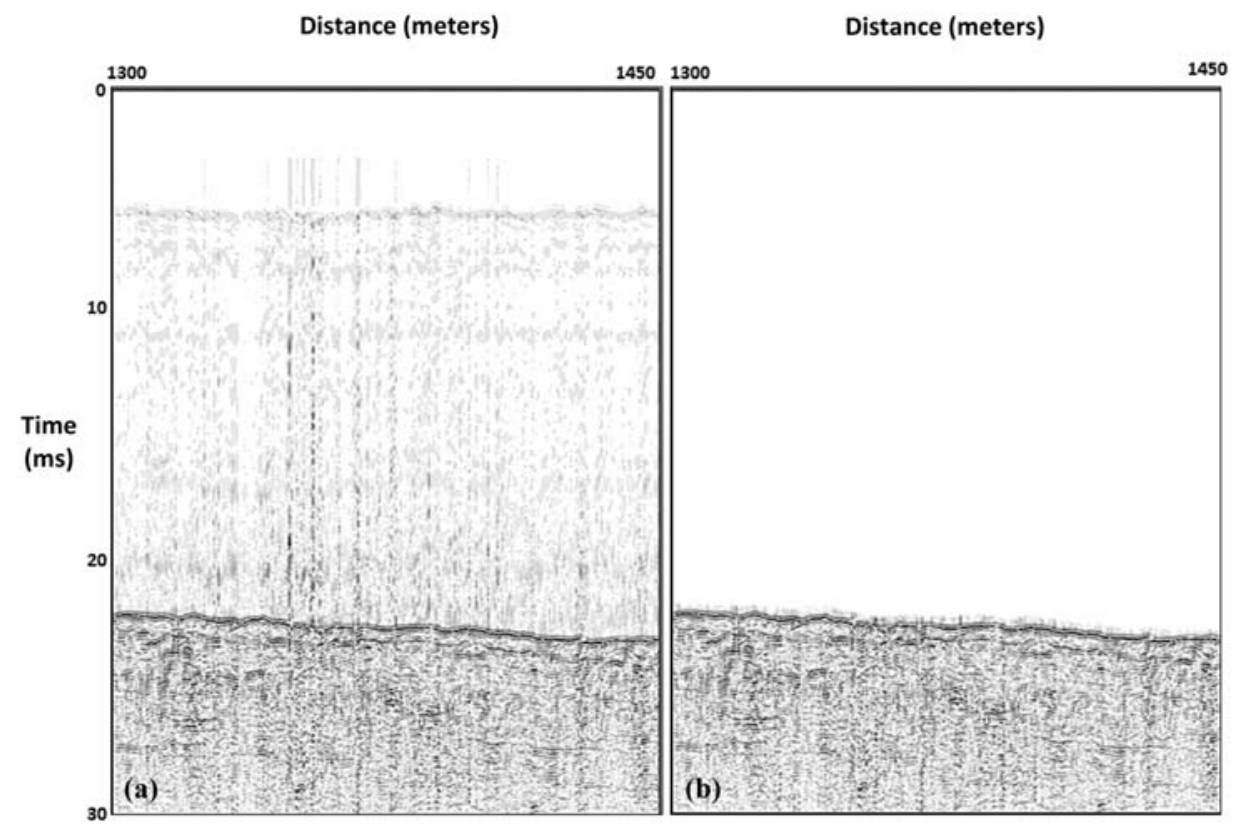

Figure 5 - Early mute applied to profile 5 (a) to eliminate the water column (b).
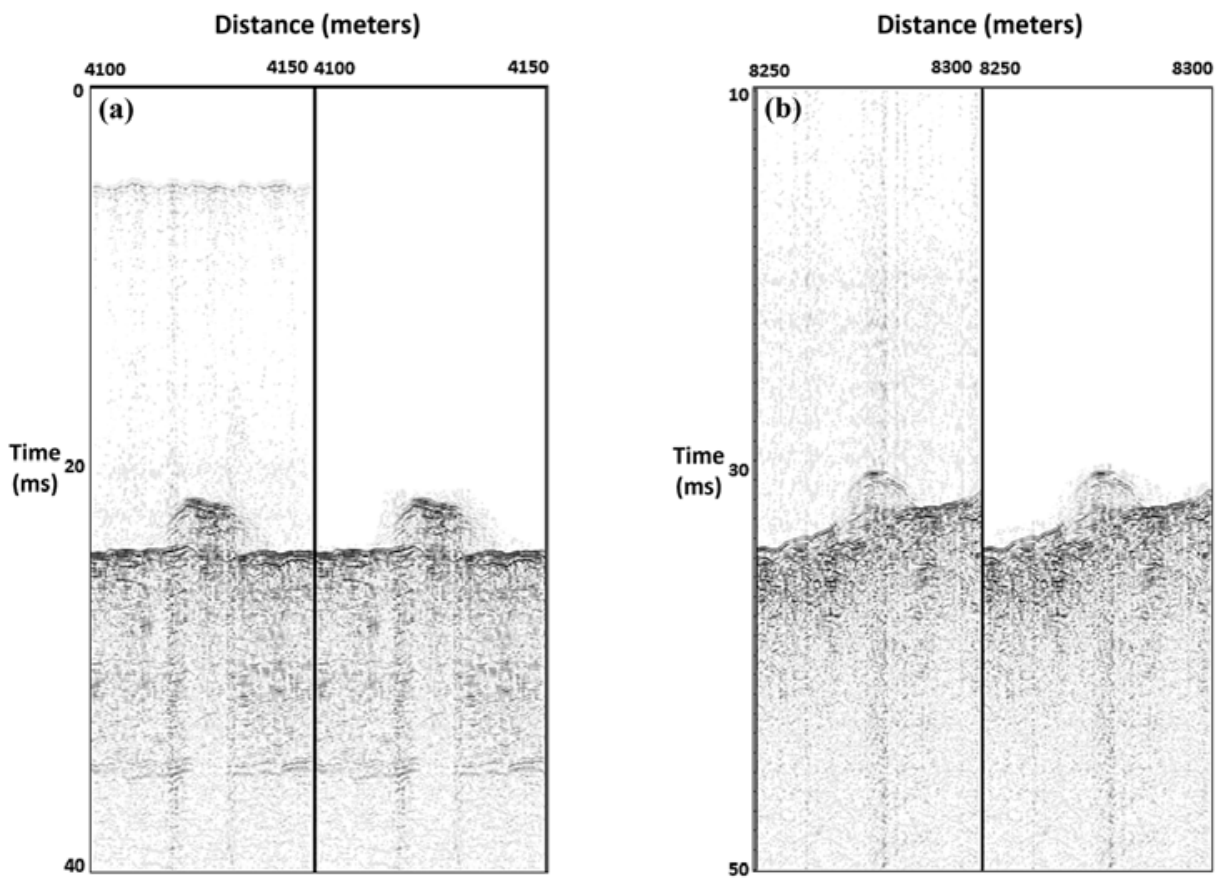

Figure 6 - Evidence of gas presence in profile 9 between the offsets 4100-4150 (a) and 8250-8300 (b). Early mute applied to the water column, preserving areas with occurrence of exhaust gas.

about amplitude and phase of seismic data spectrum. It is possible to identify more consistently the existence of noise in the amplitude spectrum data from the spectral analysis of the seismic traces. Spectral analysis should be performed before and after all the steps that use some kind of filter, in order to determine what kind of amplitude spectrum changes are caused by the filter used. For the acquired profiles, the highest energy concentrations, related the coherent signal of the subsurface reflectors, are found in the frequency range between 0.5 and $7.0 \mathrm{kHz}$, while random noise as well as instrumental and background noises are observed in 
other frequencies with lower amplitude values (Fig. 7).

During propagation of seismic pulse in a certain medium, the amount of energy contained in the wave front decays with increasing distance along the trajectory due to geometrical spreading. Energy absorption mechanisms by the medium are quite complex, but the decay can be characterized as a loss of a fixed fraction of the total energy for each oscillation of the medium particles (Kearey et al., 2002).
According to Yilmaz (1987), spectral whitening aims to correct the effects of attenuation by selecting the data in the low frequency bands, without major changes in the original signa phase. An inverse function of amplitude decay is applied to each frequency band, and the results are then summed to give the balanced trace. The comparison of the profiles (Fig. 8) shows that the non-balanced trace section (8-a) displays lateral variations and rapid energy decay along the depth due to natural attenua-

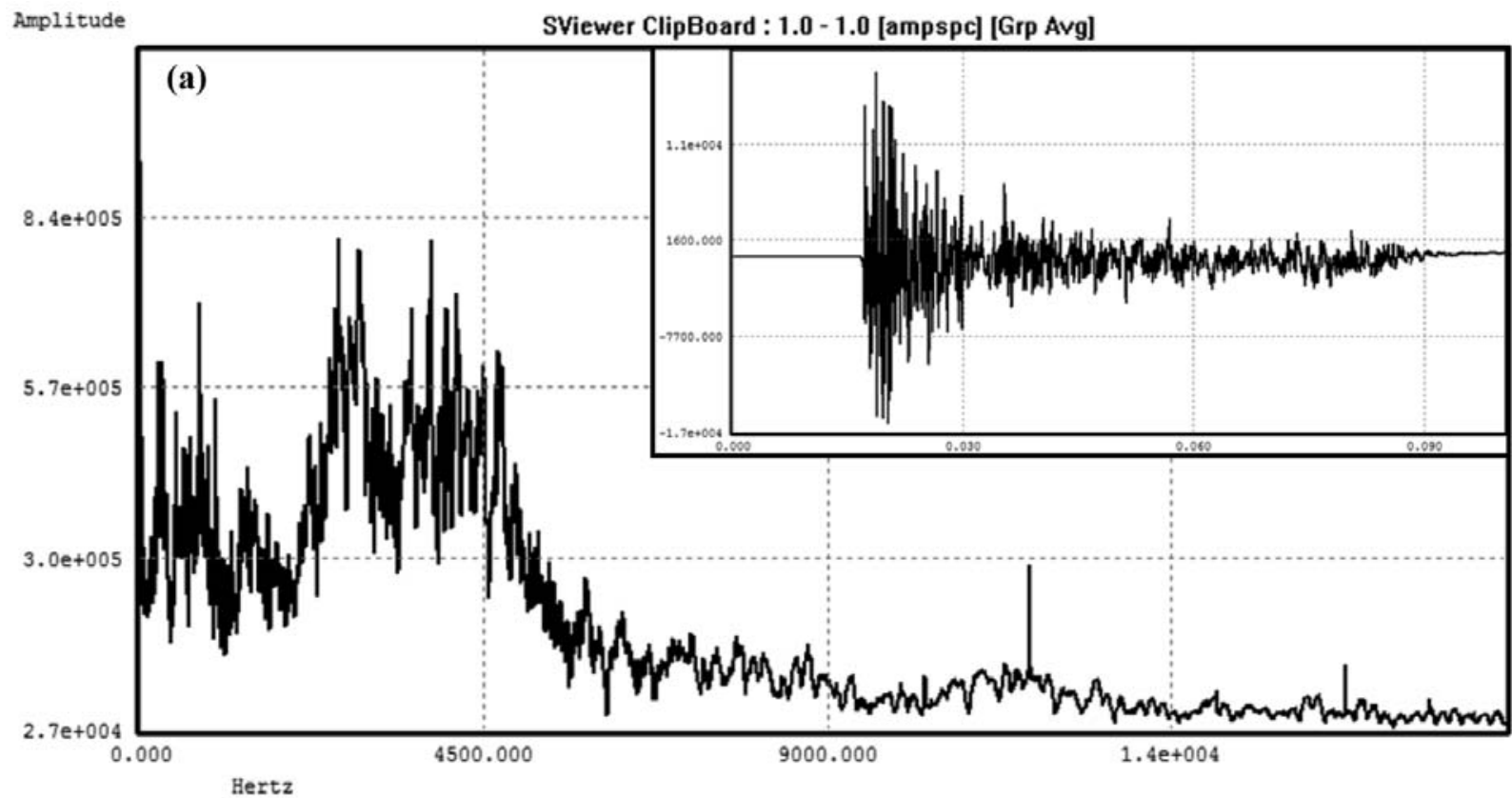

Amplitude SViewer ClipBoard : 1.0 - 1.0 [ampspc] [Grp Avg]

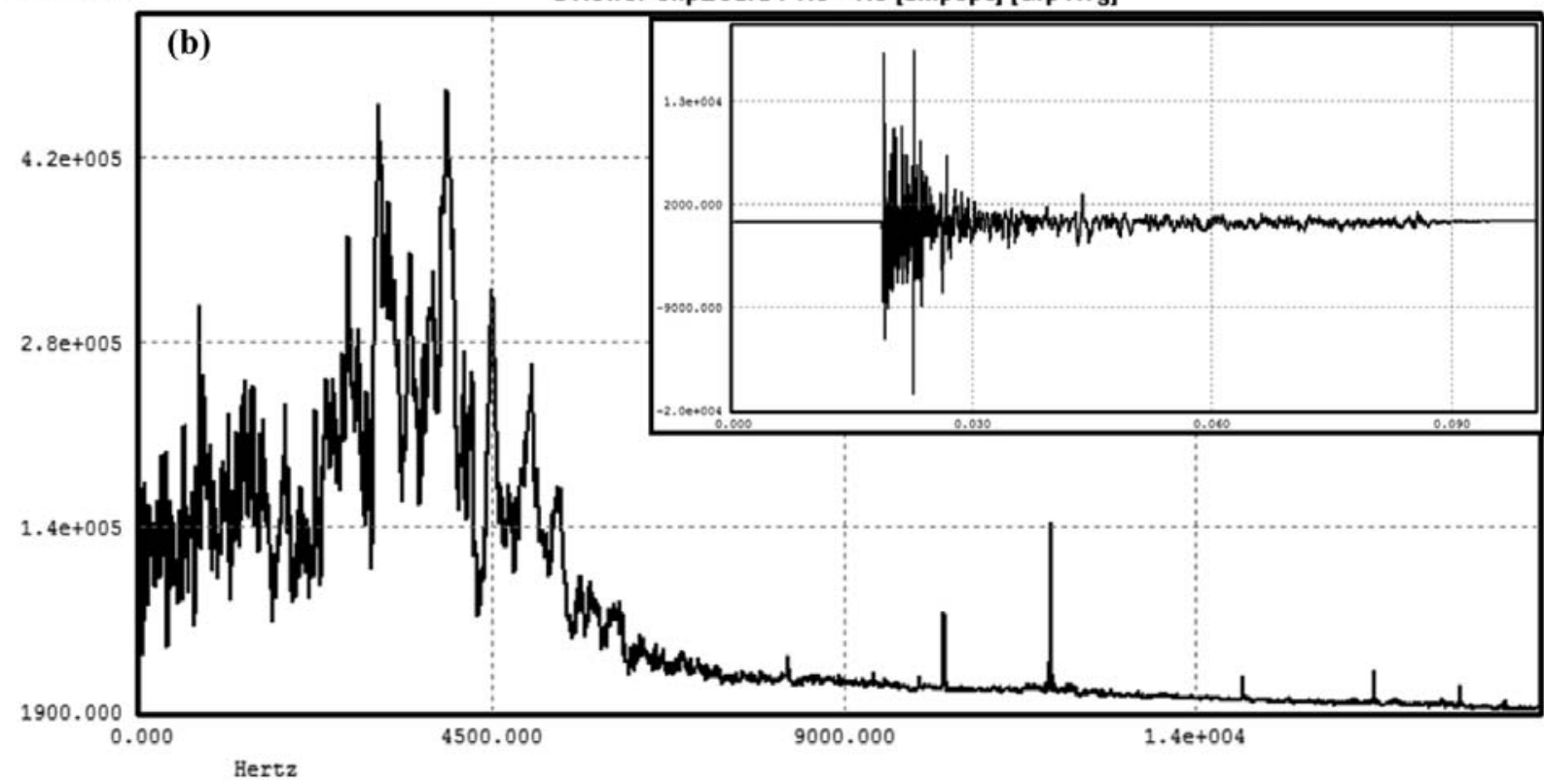

Figure 7 - Analysis of the amplitude spectrum of profile 5 (a) and profile 9 (b). 


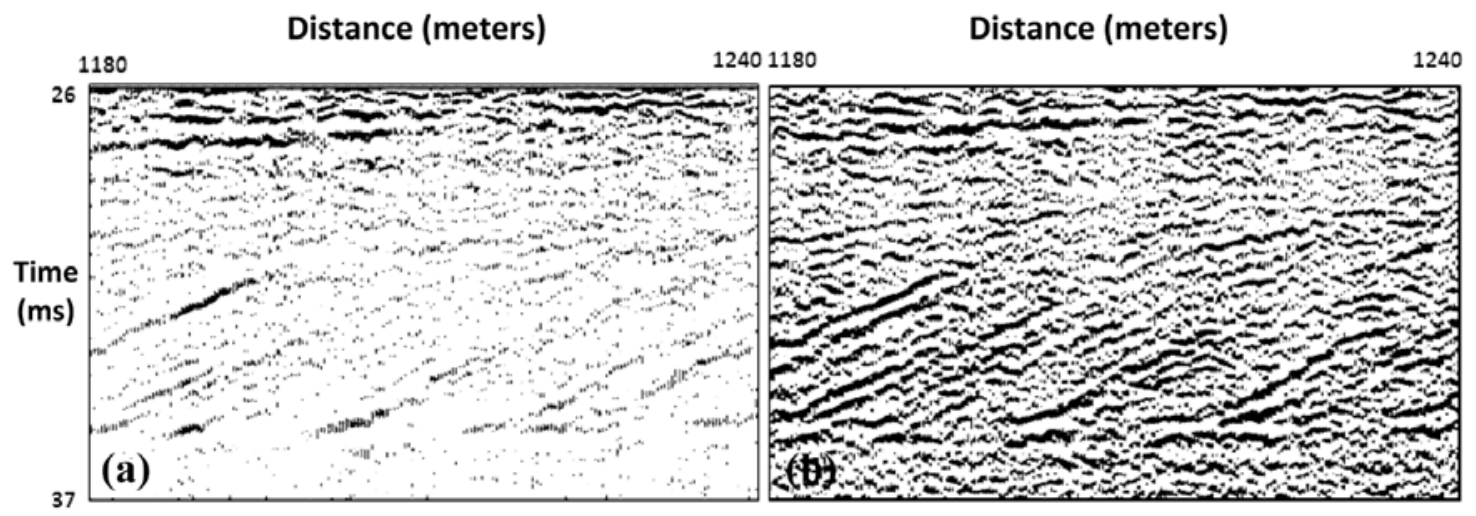

Figure 8 - Profile 9 before(a) and after (b) spectral balancing. Note the emphasis on deposits with cross stratigraphy.

tion of seismic pulse, while the seismic section after spectral balancing (8-b) shows better frequency distributions, highlighting depth events.

The signal can also be enhanced through the AGC (Automatic Gain Control), which creates an equalized distribution of signal amplitudes over time, but it should be used with caution, since it can destroy signal characteristics. In order to avoid this, an AGC snapshot can be used, where the absolute mean values of trace amplitudes are stored within an analysis window and then applied. This analysis window is then moved vertically, in time, and the entire process repeats itself until the last seismic trace data.

Highly limited analysis windows tend to cause significant signal loss while enhancing low amplitude areas, thus making stronger and weaker reflections indistinguishable from one another. Figure 9 shows this effect on the seismic section when AGC analysis windows vary for the times $3.5 \mathrm{~ms}(9-\mathrm{a}), 20 \mathrm{~ms}$ (9-b), $50 \mathrm{~ms}(9-c)$ and $100 \mathrm{~ms}(9-\mathrm{d})$.

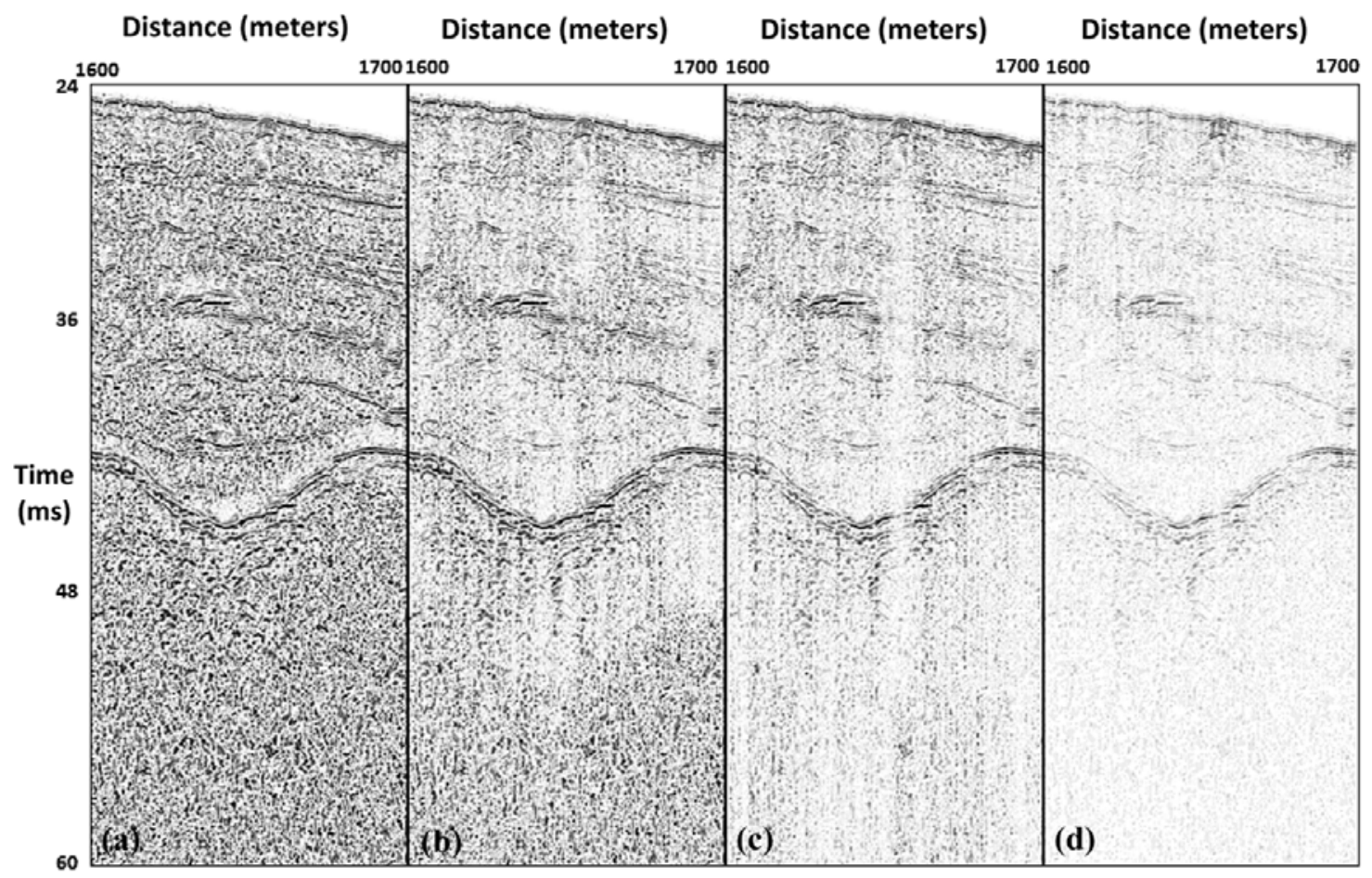

Figure 9 -Section of profile 5 showing different AGC windows applied to the data at $3.5 \mathrm{~ms}$ (a), $20 \mathrm{~ms}$ (b), $50 \mathrm{~ms}$ (c) and $100 \mathrm{~ms}$ (d). 


\section{Application of frequency filters}

Frequency filters operate on signal components in specific frequency bands so that such signal and wavelet noise components can be separated due to their distinctive features. The Butterworth filter can be used to meet the specific characteristics regarding frequency band restrictions of a seismic signal, since its frequency response enables in the band-pass, a flat response that does not alter the characteristics of the signal spectrum in this range (Oppenheim et al., 1983).

The band-pass frequency filter was designed based on the frequency distribution observed in data spectral analysis. As a result, the filtered section presents regions where a more accurate filter performance can be seen, enhancing the coherent pattern of the signal and reducing very high frequency noises, commonly found in high-resolution seismic data, thus improving the signal/noise relationship (Fig. 10). The high frequency noise creates a rectilinear pattern that crosses the seismic reflections, masking the regions of interest. The removal of such noise demands close attention since they are mixed up with signals of interest that can eliminate the reflection signal and, therefore, impair the final product. Figure 11 shows the removal of unwanted frequency content of the traces by spectral analysis after the filtering step.
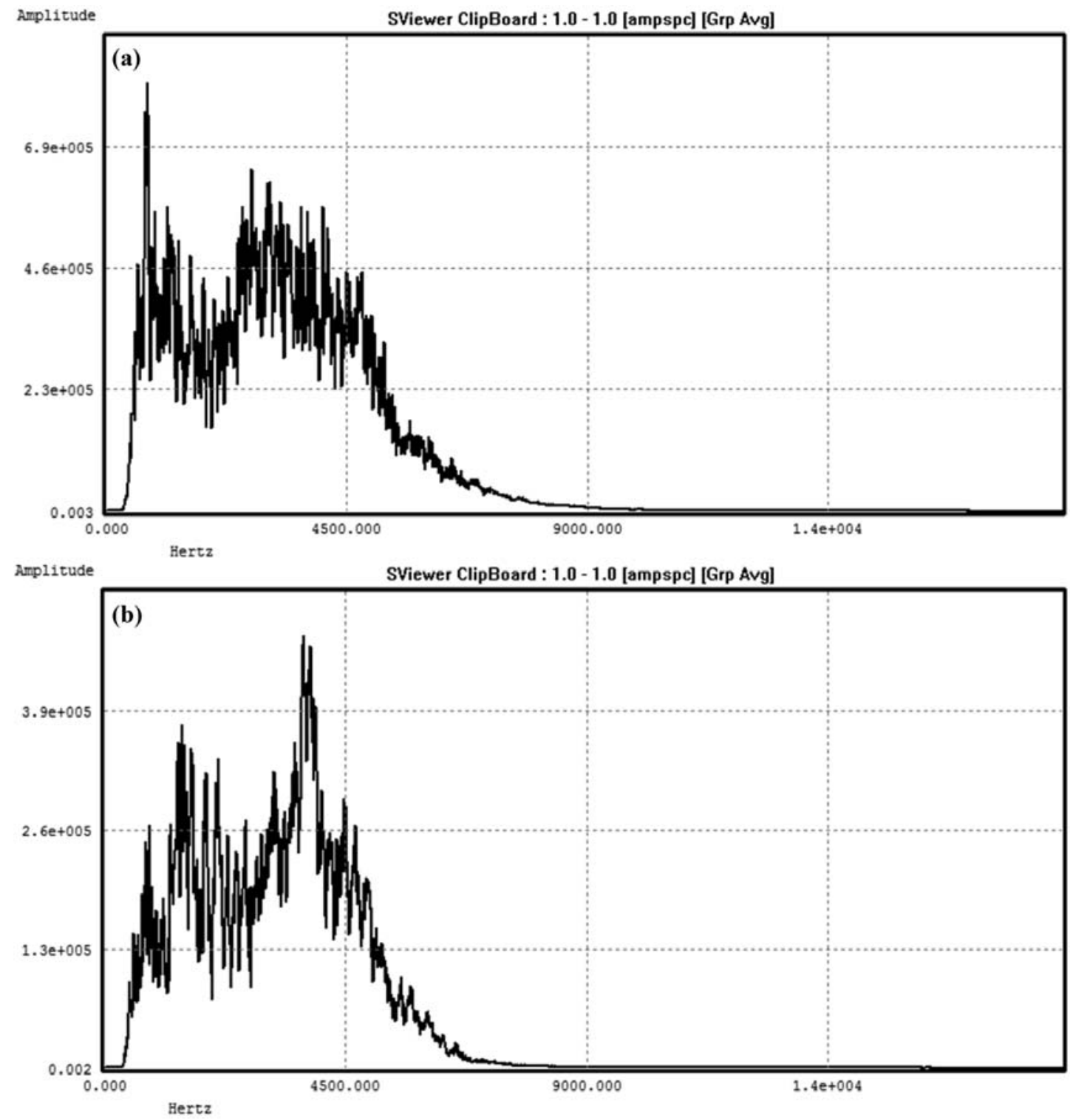

Figure 10 - Amplitude spectrum of profiles 5 (a) and 9 (b) after application of the band-pass filter. 


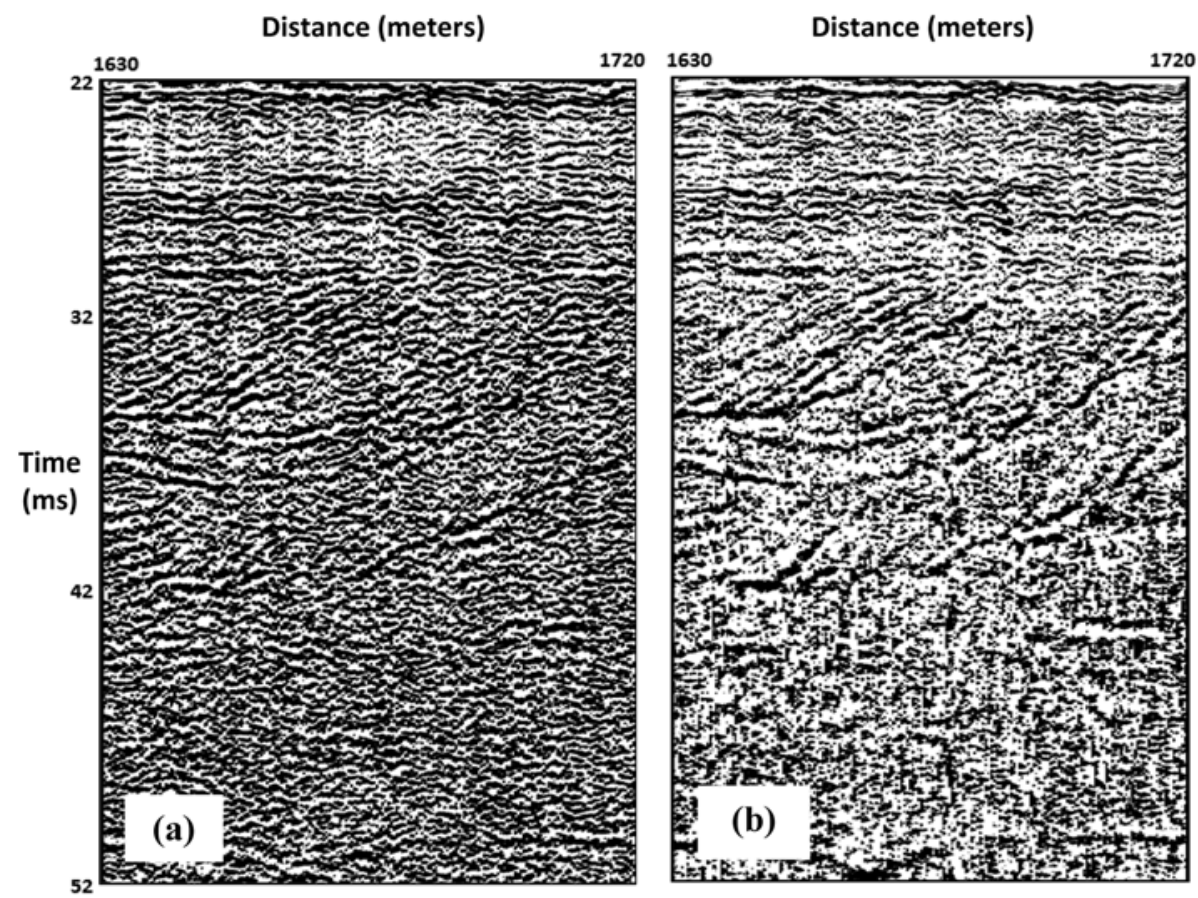

Figure 11 - Comparison between unfiltered sections (a) and after applying the band-pass filter (b), indicating the presence of buried paleochannel deposits, profile 9 .

A weighted average filter, which considers traces adjacent to the center trace and assigns importance based on this distance, was used aiming to improve the horizontal resolution and enhance the lateral continuity of subsurface horizons. The weighted average filter is considered a low-pass filter implemented from a window that may or may not be associated with a previously selected structure or horizon (Chopra \& Marfurt, 2007).

A window containing five traces was adopted for the seismic records, with the greater weight being assigned to the central trace to avoid the loss of signal integrity and decrease the signal/noise ratio, especially in dip events on subsurface where the weighted average does not yield optimum effect. Figure 12 shows a fragment of profile 9 where the improved spatial resolution and greater lateral continuity of the horizons after applying the weighted average filter can be seen.

\section{Deconvolution}

Several components of the seismic noise occur within the range of the frequency spectrum of a seismic signal, such as multiple and diffraction, called coherent noise, and cannot be removed using frequency filters. Deconvolution is the process of removing the adverse effects associated with seismic pulse propagation on subsurface. Greater distortions occur in the layers closer to the surface and are consistent with the receiver and source. Decon- volution is an attempt to recover the reflection coefficients from the theoretical trace, considering the source waveform.

In high-resolution seismic profiling is common to observe the presence of multiple reflections associated with the seabed, which may overcome the primary reflection events on the surfaces of interest. The cyclic interference of wave trains amplified from individual horizons, seriously degrades the seismic records making its identification nearly impossible. Usually, the multiple reflections have the same frequency band of signal, and the predictive deconvolution is a useful tool in its removal. It can also be used to improve the imaging of thinner thin layers, not visible in the raw signal.

The best results for treating the seismic data were obtained using predictive deconvolution, attenuating the multiples and overlapping reverberations that mitigated the subsurface reflections (Fig. 13). Basically, the predictive deconvolution algorithm attempts to remove the effects of multiples by predicting their arrival times, and based on the arrival times of primary events, that is, related reflectors, assuming that there is no systematic pattern for the distribution of reflection interfaces and that the waveform of a minimum phase impulsive source has energy concentrated on the pulse front (Robinson \& Treitel, 2000). The application of predictive deconvolution aimed at removing background multiples and improving data vertical resolution. 


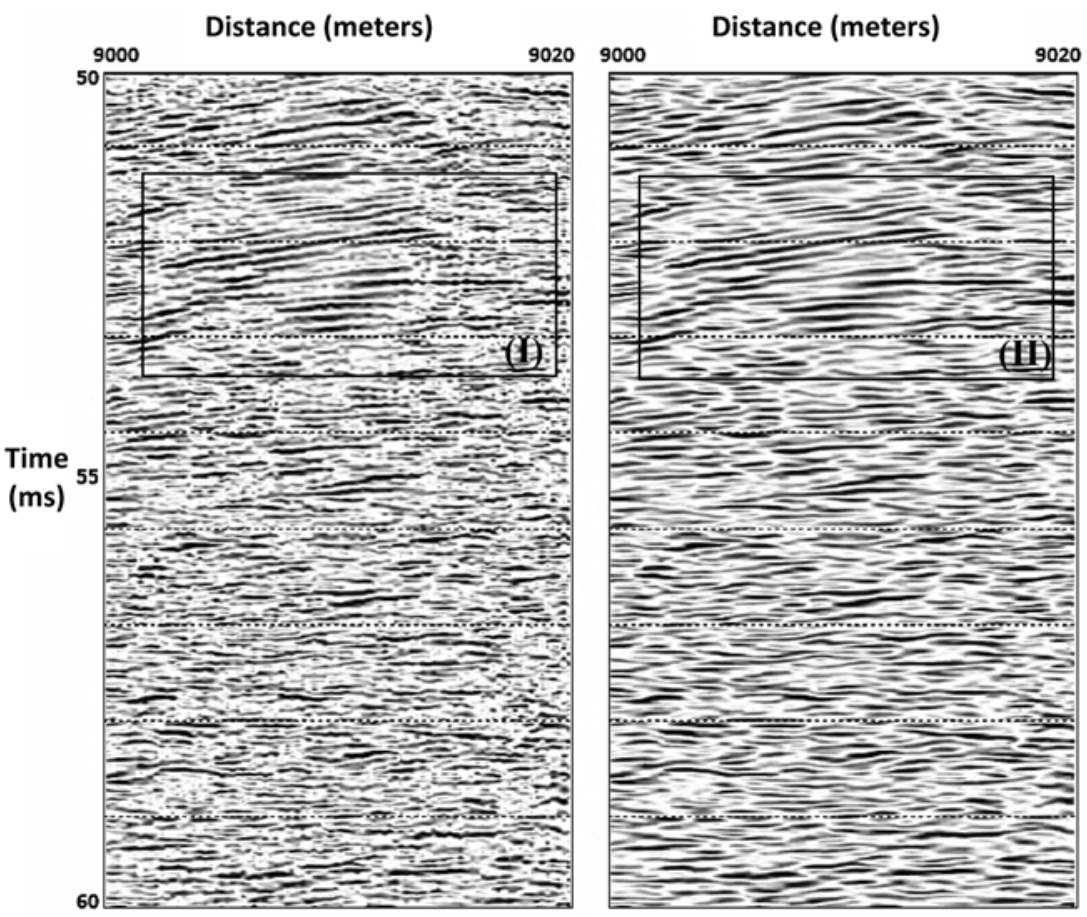

Figure 12 - Application of the moving average filter. The comparison between frames (I) and (II) shows improvement in the lateral continuity of the horizons with respect to raw data.

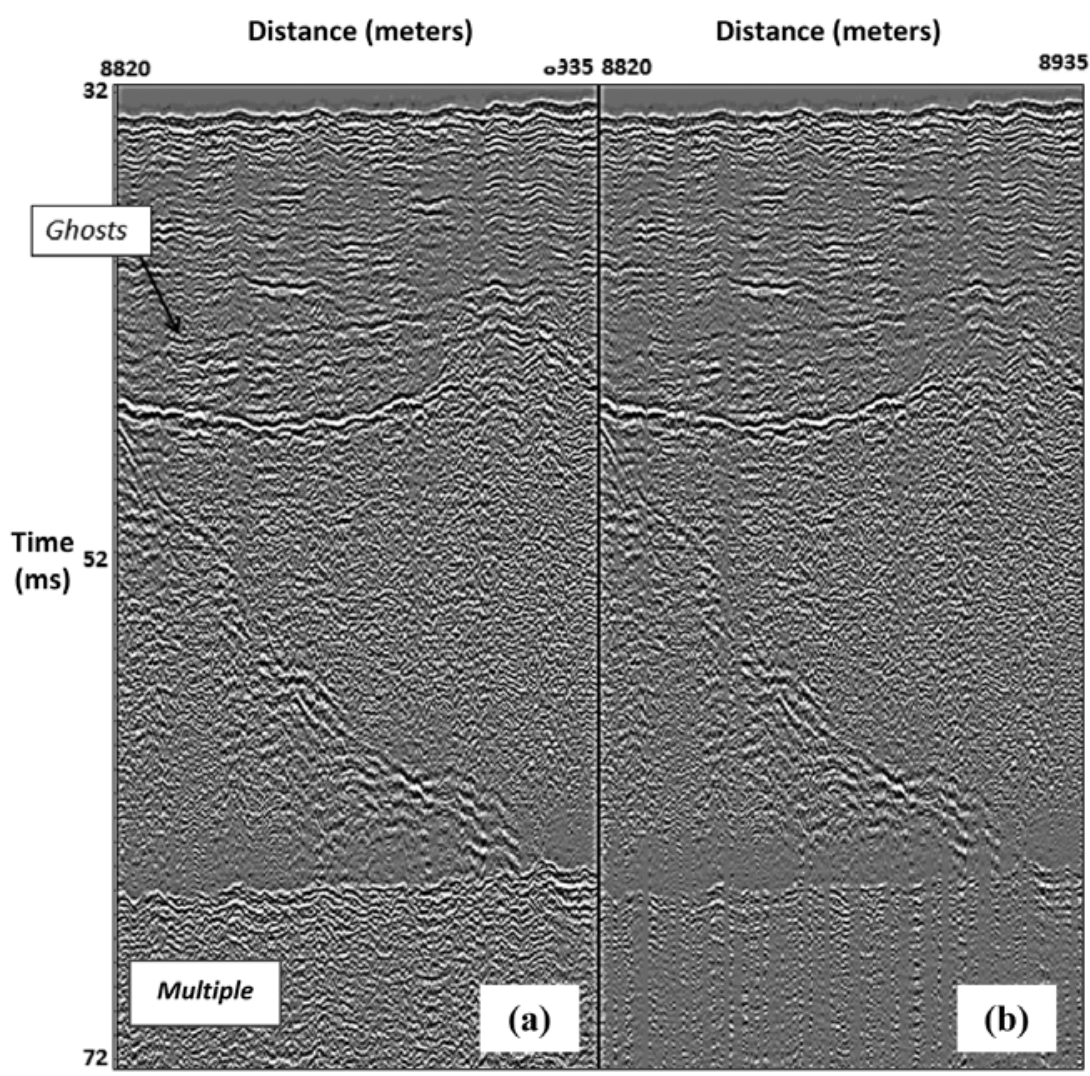

Figure 13 - Attenuation of bottom multiple and deghosting after deconvolution step. Before (a) and after (b). 


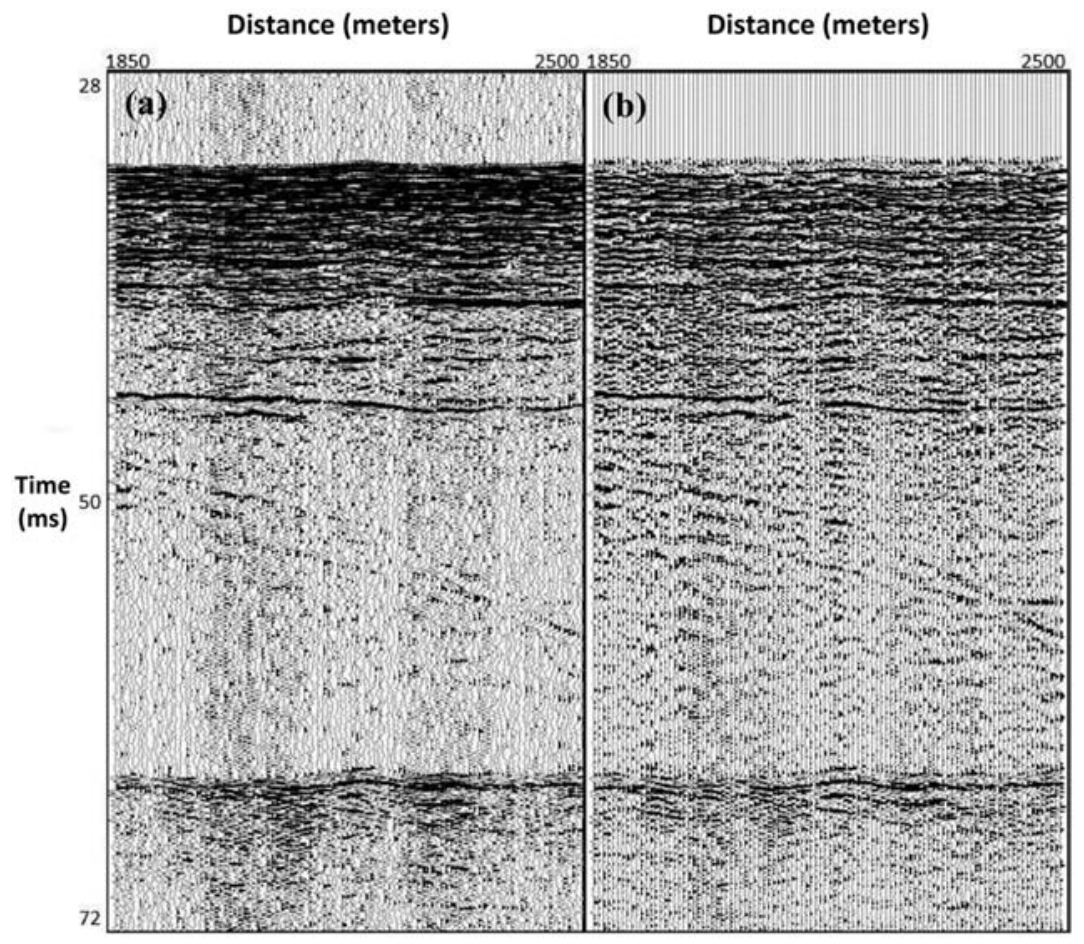

Figure 14 - Raw profile (a) and after the processing steps(b).

There are still several gaps on the removal process of multiples in shallow seismic data. In most cases deconvolution cannot attenuate the multiples, particularly those related to the presence of shallow gas which has quite high amplitudes, as observed in the studied profile (Fig. 14). In these cases, the use of more than one window, a deconvolution operator or the application of SRME are suggested.

\section{$2^{\text {nd }}$ Data filtering}

Subsequent to the deconvolution step, the data were filtered again to eliminate artifacts generated in the seismic wavelet compression. The filter parameters of the first cleaning step remained the same, supported by the fact that applying the deconvolution algorithm generates coherent high frequency noise, requiring a further low-pass filter.

\section{Interpretation of seismic profiles}

Figures 15 and 16 correspond respectively to cropped sections of profiles 5 and 9 before and after the processing steps. The sedimentary deposits of Guanabara Bay, observed in high-resolution seismic, reveals a series of erosion and sediment filled events, with numerous paleovalleys and buried paleochannels, featuring at least three major distinct filling phases on the acoustic base- ment: eroded fluvial paleochannels and paleovalleys (I), drowning deposits showing cross bedding and propagation toward the mainland (II) and current sedimentation featuring finer particles toward the inner portion of the bay (III).

The lower portion (I) appears to be associated with deposition environments and fluvial dynamics due to its seismic unit acoustic features and very irregular geometry. The first layer above the acoustic basement display a highly irregular contour featuring numerous inner erosion surfaces, showing various filled paleochannels, with clear evidence of deposits associated with channel lateral progradation and total thickness of about 15 to $20 \mathrm{~m}$, tapering as it enters the bay.

The intermediate unit (II) has thickness varying from 5 to $10 \mathrm{~m}$, displays softer reflectors compared to the lower portion indicating parallel-plane sedimentation, slightly crossed from the edge of the bay, with at least one internal discordant surface and small filled channels. Thus, it is believed that this portion represents the current and sub-current estuarine deposits of the bay.

The upper portion (III) represents the current deposition of the bay, strongly influenced by the decreasing energy of the innermost portions. In the north bay, shallow gas pockets occur more often, also evidenced by columns of multiples, and there is also in some places, exhaust gas into the water column. 


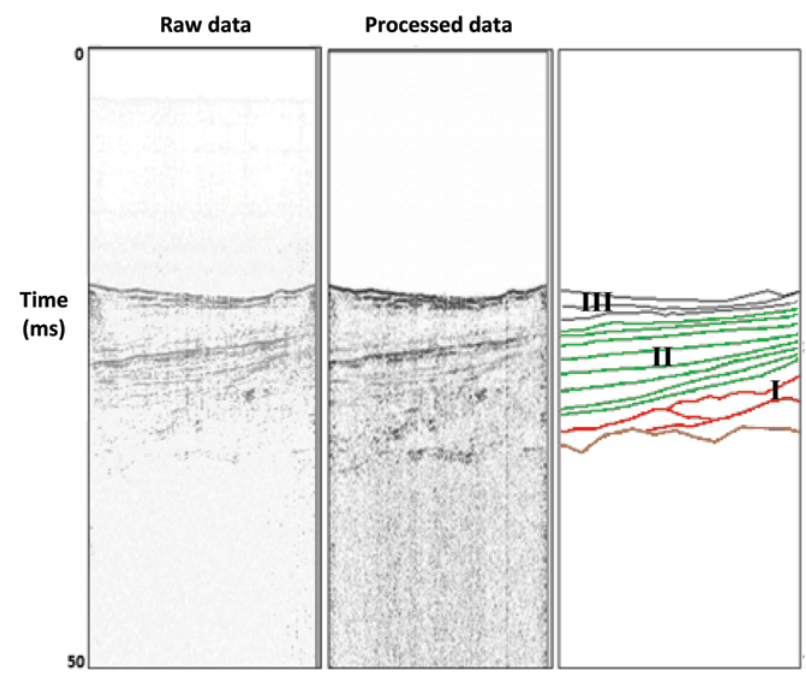

Figure 15 - Comparison between raw and processed data, profile 5.

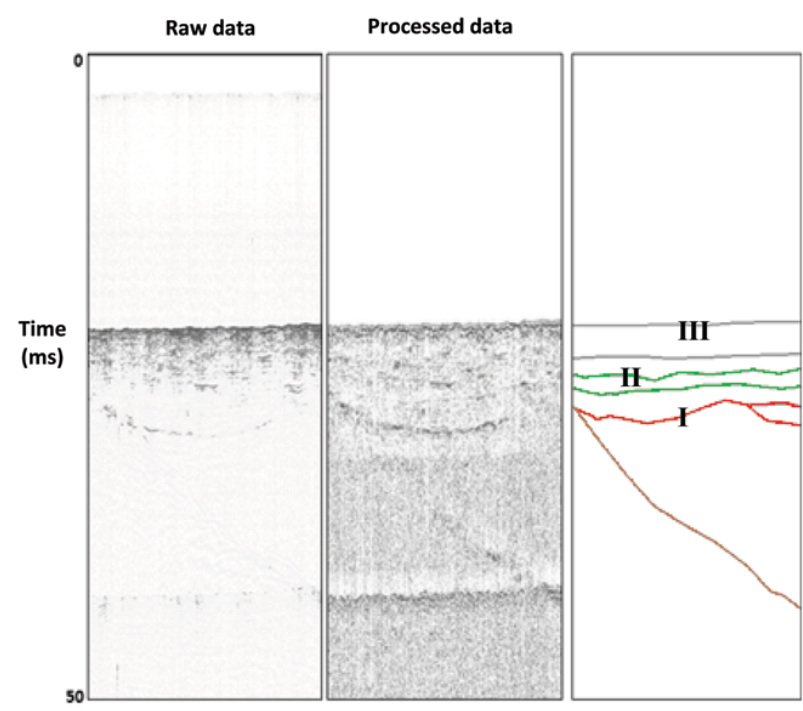

Figure $\mathbf{1 6}$ - Comparison between raw and processed data, profile 9.

\section{CONCLUSIONS}

The application of different geophysical techniques has shown to be a highly feasible solution to study coastal environments, such as assessing the impact of human activities on them. The main objective of this work was to process the high-resolution seismic data, targeting the Quaternary sedimentary deposits of Guanabara Bay. In summary, the main results of this study are:

- The simple processing flowchart used to search for wellmarked reflectors modified only slightly the raw data. The available literature proved quite limited regarding the processing of high-resolution seismic, addressing especially surveys in regions of relatively simple geology;
- Too restrictive gain windows tend to cause significant degradation of the signal while enhancing low amplitude areas, thus making stronger and weaker reflections indistinguishable from one another;

- After testing different filtering techniques aiming to increase the signal/noise ratio, significant improvements were observed in reflector imaging;

- Using a five-trace window average filter was shown to be very efficient to improve lateral continuity of reflectors, except in regions where the reflectors are very inclined, since this filter was not very effective in these regions; 
- One of the problems that degraded the most the quality of the records was the constant presence of reverberations and ghosts. The application of predictive deconvolution showed good results in mitigating them, without this filter, trace interpretation would be severely compromised;

- The sedimentary deposits of Guanabara Bay revealed three distinct deposition phases over the crystalline basement, interpreted in the seismic record as: fluvial (I) - marked by a very irregular surface related to lateral migration of the channels; sub-current estuarine (II) - softening the irregular morphology, related to the drowning of the fluvial paleosystem; and current estuarine (III) - plain-parallel reflectors associated with the decrease of relative sea level;

- The implementation of a processing flowchart to treat high-resolution seismic data proved quite promising since it enhanced features not observed before in the interpretation of seismic records.

\section{ACKNOWLEDGEMENTS}

The authors are very thankful to PETROBRAS/Agência Nacional do Petróleo (ANP) for the financial support given to the Department of Geology and Geophysics at Universidade Federal Fluminense and for the availability of the facilities and equipment used in this work.

\section{REFERENCES}

AMADOR ES. 1980. Unidades sedimentares cenozóicas do recôncavo da baia de Guanabara (folhas Petrópolis e Itaborai). Proceedings... Academia Brasileira de Ciências, 52(4): 743-761.

AMADOR ES. 1997. Baía de Guanabara e ecossistemas periféricos: homem e natureza. UFRJ. Rio de Janeiro. 539 pp.

BAPTISTA NETO JA, SILVA MAM \& FIGUEIREDO Jr. AG. 1996. Sísmica de alta frequência e 0 padrão de distribuição de sedimentos na enseada de Jurujuba (Baía de Guanabara) - RJ/Brasil - Revista Brasileira de Geofísica, 14(1): 51-57.

BAPTISTA NETO JA, BREHME I, GINGELE FX \& LEIPE T. 2006. Spatial distribution of heavy metals in superficial sediments from Guanabara bay: Rio de Janeiro, Brazil. Environmental geology, 49: 1051-1063.

BARROS GLM. 2006. Navegando com a eletrônica. $2^{\mathrm{a}}$ Ed. Petrópolis, RJ. Catedral das Letras. $392 \mathrm{pp}$.

BRUNETTA R. 2005. 0 processamento da sísmica de reflexão rasa Desafios encontrados no estudo de modelos análogos a reservatórios fraturados. Master Dissertation. Universidade Federal do Paraná Curitiba, PR, 94 pp.

CATANZARO LF, BAPTISTA NETO JA, GUIMARÃES MSD \& SILVA CG. 2004. Distinctive sedimentary processes in Guanabara Bay - SE/Brazil, based on the analysis of echo-character $(7.0 \mathrm{kHz})$. Revista Brasileira de Geofísica, 22(1): 69-83.

CHOPRA S \& MARFURT KJ. 2007. Seismic attributes for prospect identification and reservoir characterization. SEG Books. 464 pp.

DIAS GTM \& KEJRFVE B. 2008. Geology and geomorphology of Holocene coastal barriers of Brazil. Louisiana State University. SpringerVerlag Berlin and Heidelberg \& Co; 7: 225-252.

GOMES MP, VITAL H \& MACEDO JWP. 2010. Fluxo de processamento aplicado a dados de sísmica de alta resolução em ambiente de plataforma continental. Exemplo: Macau-RN. Revista Brasileira de Geofí́sica, 29(1): 173-186.

HOULDING SW. 1994. 3-D Geoscience Modeling Computer Techniques for Geological Characterization. Springer-Verlag. Berlin. 309 pp.

KEAREY P, BROOKS M \& HILL I. 2002. An introduction to Geophysical Exploration. Blackwell Scientific. Oxford (UK). 438 pp.

KJERFVE B, RIBEIRO CHA, DIAS GTM, FILIPPO AM \& QUARESMA VS. 1997. Oceanographic characteristics of an impacted coastal bay: Baía de Guanabara, Rio de Janeiro, Brazil. Continental shelf research, 17(13): 1609-1643.

LOWRIE W. 2006. Fundamentals of geophysics. $17^{\mathrm{a}}$ Ed. United Kingdom. Cambridge University Press. 354 pp.

OPPENHEIM AV, WILLSKY AS \& YOUNG IT. 1983. Signals and Systems. Prentice-Hall, Englewood Cliffs, $796 \mathrm{pp}$.

QUARESMA VS. 1997. Caracterização da dinâmica sedimentar da Baía de Guanabara, RJ. Master Dissertation - LAGEMAR-UFF. Niterói. 97 pp.

QUARESMA VS, DIAS GTM \& BAPTISTA NETO JA. 2000. Caracterização da ocorrência de padrões de sonar de varredura lateral e sísmica de alta freqüência (3,5 e 7,0 khz) na porção sul da baía de Guanabara - RJ. Revista Brasileira de Geofísica, 18(2): 201-214.

ROBINSON EA \& TREITEL S. 1980. Geophysical Signal Analysis. Prentice-Hall, Englewood Cliffs, $466 \mathrm{pp}$.

ROBINSON EA \& TREITEL S. 2000. Geophysical Signal Analysis. Society of Exploration Geophysicists, Tulsa,USA. 516 pp.

RUELLAN F. 1944. Evolução geomorfológica da Baía de Guanabara e das regiões vizinhas. Revista Brasileira de Geografia, 6(4): 445-508.

YILMAZ 0. 1987. Seismic Data Processing. SEG Books. 534 pp. 


\section{NOTES ABOUT THE AUTHORS}

Igor Kestemberg Marino received his B.Sc. in Geophysics at Universidade Federal Fluminense in 2013. He currently works at PGS - Rio Office, with the Imaging and Engineering team, as a Junior Geophysicist on marine seismic processing projects.

Marco Antonio Cetale Santos received his B.Sc. in Electronics Engineer at Universidade Estadual do Rio de Janeiro in 1996, his M.Sc. and D.Sc in Electric Engineer at Pontificia Universidade Católica of Rio de Janeiro in 1998 and 2003, respectively. Professor of the Department of Geology and Geophysic of Universidade Federal Fluminense since 2009. Presently is the head of department since 2012. His interest are in Seismic Processing and Imaging; Seismic Inversion; Anisotropy, Elastic and Acoustic Modeling; Signal processing and Data Compression.

Cleverson Guizan Silva B.Sc. and M.Sc. in Geology at Universidade Federal do Rio de Janeiro (UFRJ) in 1982 and 1987. Ph.D. in Geology at Duke University obtained in 1991. Professor of the Department of Geology and Geophysics at Universidade Federal Fluminense since 1985. Research Scholar of CNPq. 